\title{
Acute hospital dementia care: results from a national audit
}

\author{
Suzanne Timmons ${ }^{1}$, Emma O'Shea ${ }^{1 *}$, Desmond O'Neill², Paul Gallagher ${ }^{1}$, Anna de Siún, Denise McArdle, \\ Patricia Gibbons ${ }^{3}$ and Sean Kennelly ${ }^{2}$
}

\begin{abstract}
Background: Admission to an acute hospital can be distressing and disorientating for a person with dementia, and is associated with decline in cognitive and functional ability. The objective of this audit was to assess the quality of dementia care in acute hospitals in the Republic of Ireland.

Methods: Across all 35 acute public hospitals, data was collected on care from admission through discharge using a retrospective chart review $(n=660)$, hospital organisation interview with senior management $(n=35)$, and ward level organisation interview with ward managers $(n=76)$. Inclusion criteria included a diagnosis of dementia, and a length of stay greater than 5 days.

Results: Most patients received physical assessments, including mobility (89\%), continence (84\%) and pressure sore risk (87\%); however assessment of pain (75\%), and particularly functioning (36\%) was poor. Assessment for cognition (43\%) and delirium (30\%) was inadequate. Most wards have access at least 5 days per week to Liaison Psychiatry (93\%), Geriatric Medicine (84\%), Occupational Therapy (79\%), Speech \& Language (81 \%), Physiotherapy (99\%), and Palliative Care (89\%) Access to Psychology (9\%), Social Work (53\%), and Continence services (34 \%) is limited. Dementia awareness training is provided on induction in only 2 hospitals, and almost half of hospitals did not offer dementia training to doctors (45\%) or nurses (48\%) in the previous 12 months. Staff cover could not be provided on $62 \%$ of wards for attending dementia training. Most wards (84 \%) had no dementia champion to guide best practice in care. Discharge planning was not initiated within $24 \mathrm{~h}$ of admission in $72 \%$ of cases, less than $40 \%$ had a single plan for discharge recorded, and $33 \%$ of carers received no needs assessment prior to discharge. Length of stay was significantly greater for new discharges to residential care $(p<.001)$.

Conclusion: Dementia care relating to assessment, access to certain specialist services, staffing levels, training and support, and discharge planning is sub-optimal, which may increase the risk of adverse patient outcomes and the cost of acute care. Areas of good practice are also highlighted.
\end{abstract}

Keywords: Dementia, Quality of care, Hospitals, Audit, Assessment, Antipsychotics, Discharge planning, Specialist services, Staff training

\section{Background}

Dementia is characterized by progressive impairment in domains such as memory, orientation, comprehension, language, and judgement and can also affect personality, mood and behaviour. In Ireland, approximately 41,700 people were estimated to have dementia as of 2006 , and this figure is projected to rise to between 140,580 and

\footnotetext{
*Correspondence: emma.oshea@ucc.ie

${ }^{1}$ Centre for Gerontology and Rehabilitation, School of Medicine, University College Cork, The Bungalow, Block 13, St. Finbarr's Hospital, Douglas Road, Cork, Ireland

Full list of author information is available at the end of the article
}

147,000 by 2041 [1], making it a significant public health issue. According to the World Health Organisation [2], the rapidly increasing prevalence of dementia will place unprecedented demands on health care services, challenging governments to develop and improve the services providing care for people with dementia, in order to meet these demands.

Older people with dementia on average have three or more physical comorbidities, which at some point necessitate hospital admission [3] and the prevalence of dementia in hospital ranges from $29-42 \%$ in adults over 70 
$[4,5]$. Hospital admission is distressing for this population and is associated with cognitive and functional decline [6], greater institutionalisation post-discharge [7, 8], and higher mortality rates $[5,7]$.

Acute hospitals are not currently equipped to provide best dementia care [9]. Patients are generally not hospitalized for the dementia itself [10] and therefore the dementia is rarely the care or treatment priority. Further, staff training and knowledge around dementia care can be poor $[9,11]$ and it often goes undetected in the acute setting [12]. This can result in unmet needs, and an increase in behavioural and non-cognitive symptoms of dementia (BPSD) [13], which staff report to be burdensome [14]. Other factors contributing to poor quality dementia care in hospitals include poor multidisciplinary assessment, $[15,16]$, under-diagnosis and treatment of pain [17], failure to collect collateral history [18], and the inappropriate prescription of antipsychotic drugs [19].

A diagnosis of dementia is also related to greater length of stay (LOS) in hospitals [20], and an increased cost of care. Dementia care is estimated to cost $€ 21$ million per annum in Ireland, based on the number of Hospital In-Patient Enquiry (HIPE)-coded discharges of people with a recorded formal diagnosis of dementia [1]. A more recent study has estimated that dementiarelated admissions lead to approximately 246,908 additional days per annum in hospitals in Ireland, at an associated cost of $€ 199$ million [21]. Reasons cited for increased LOS are largely systemic, include poor discharge planning, delayed discharge relating to posthospital care availability for complex conditions, and lack of communication and coordination between health service providers $[22,23]$.

It is clear from the above literature that improving dementia care in acute hospitals should be an urgent priority in Ireland. Countries including England and Wales $[15,16]$ have carried out audits of dementia care to gain a baseline picture of the quality of care provision in their hospitals. The objective of this audit is to assess, for the first time, the quality of dementia care in acute public hospitals in the Republic of Ireland.

\section{Method}

As there are no standards in place for dementia care in acute hospitals in Ireland currently, this audit measured care against international best practice guidelines.

All 35 acute public hospitals admitting adults within the Health Service Executive (HSE) were included in this audit, and the data was collected between April and September 2013. The audit tools were developed for use in the National Audit of Dementia Care in General Hospitals in England and Wales [15], and with permission from the Healthcare Quality Improvement Partnership, minor alterations were made to the wording of questions, where necessary, so that they made sense in the context of the Irish healthcare system.

For this audit, (i) a retrospective chart review tool, as well as (ii) hospital level organisation (iii) ward level organisation (iv) and ward environment tools were employed. The results of the ward environment module of the audit are not reported here.

(i) Chart Review: This tool tracked the quality of care received by patients $(n=660)$ retrospectively, from admission through to death/discharge during a single admission, collecting information on demographics, assessments carried out on or during admission, referral to specialist services and discharge planning. Charts were identified using the HIPE system which collects national demographic, clinical and administrative data on discharges from, and deaths in all acute public hospitals. Inclusion criteria included a recorded HIPE diagnosis (primary or other) of dementia (International Classification of Disease (ICD)-10 codes: F00, F01, F02, F03, F05.1), a LOS greater than 5 days, and a hospital discharge date between $1^{\text {st }}$ September 2012 and $31^{\text {st }}$ January 2013.

The data was collected by the audit team as well as Specialist Registrar trainees in geriatric medicine, all of whom received comprehensive training in the use of the audit tool. Where possible, hospitals had their charts reviewed by independent auditors (76\%). Furthermore, $25 \%$ of charts were independently re-reviewed by the audit team. The tool was found to have good inter-rater reliability and percentage agreement, similar to that found in the England \& Wales audit [15].

(ii) Hospital Organisation: The audit team used this tool to collect data on hospitals' $(n=35)$ policies, procedures, structures and guidelines relating to dementia care, through structured interview with senior hospital management and clinicians.

(iii) Ward Organisation: This tool collected data on staffing levels and supports, availability of specialist services, and systems in place to support people with dementia on wards through structured interview with the ward manager. In each hospital, 2-3 wards that admit adults were selected, with at least one medical and one surgical ward chosen per hospital. In total, 77 wards were audited by the audit team.

\section{Data analysis}

Most of the data collected was categorical in nature, and valid percentages are reported in this study to describe this data. Median and interquartile ranges were used to describe the distribution of continuous variables, 
including age and LOS as the data did not have a normal distribution. For this same reason, the Mann-Whitney U-Test (non-parametric equivalent of the T-test) was used to investigate group differences in continuous variables. Data were analysed using SPSS version 20.

\section{Ethics}

As this was an approved national audit, performed in partnership with the Health Service Executive's National Quality and Patient Safety Directorate, we were exempt from seeking multiple hospital-level ethical committee approvals. Data collectors external to a hospital signed confidentiality agreements and access to charts at each site was coordinated through the hospital's audit/quality department. Each hospital was assigned a code, kept securely by the audit coordinator, and individual hospitallevel data was only released to that hospital's Executive Officers. Similarly, each patient's chart was assigned a code at source (to allow the re-audit of some charts for quality assurance) and no identifying patient details were recorded. The linking code was kept securely in the hospital's audit/quality department and destroyed at the end of the audit.

\section{Results}

\section{Demographics}

Table 1 contains information about hospital size groupings as determined by bed capacity, as well as the number of geriatricians, hospitals and charts reviewed per group. Patient $(n=660)$ demographics relating to sex, age, place of admission, and ward type can be found in Table 2; few patients were treated according to an end of life care pathway or referred to specialist palliative care and a decision for resuscitation was documented in less than half of charts. Inhospital death occurred in less than $8 \%$. Of those who survived the admission, most were discharged to residential care or home, with $35 \%$ of those originally admitted from home being newly institutionalised. The median LOS was 12 days (IQR $=7-28$ ), however a Mann-Whitney $U$ test revealed that LOS was significantly greater for those newly discharged to residential care $($ median $=35)$, than not ( median $=10$ ), $U=13024, z=-10.67, p<0.001$.

Table 1 Hospital characteristics and charts reviewed by bed

\begin{tabular}{lllll} 
capacity & \multicolumn{1}{l}{$\begin{array}{l}80-150 \\
\text { beds }\end{array}$} & $\begin{array}{l}151-300 \\
\text { beds }\end{array}$ & $\begin{array}{l}301-600 \\
\text { beds }\end{array}$ & $\begin{array}{l}601-1000 \\
\text { beds }\end{array}$ \\
\hline $\begin{array}{l}\text { Number of geriatricians in } \\
\text { the hospital }\end{array}$ & $1-2$ & $2-3$ & $2-4$ & $3-5$ \\
$\begin{array}{l}\text { Number of hospitals } \\
\text { Number of Charts Reviewed }\end{array}$ & 9 & 9 & 12 & 5 \\
\hline
\end{tabular}

Table 2 Patient demographic information

\begin{tabular}{ll}
\hline Sex (\% female, $\mathrm{n})$ & $61.8,408$ \\
Age (Median, IQR) & $83,79-87$ \\
Admitted from home $(\%, \mathrm{n})$ & $62.1,410$ \\
Admitted from residential care $(\%, \mathrm{n})$ & $32.7,216$ \\
Admitted to Medical Ward $(\%, \mathrm{n})$ & 66,436 \\
Admitted to Care of the Elderly Ward $(\%, \mathrm{n})$ & $9.1,60$ \\
Admitted to Surgical Ward $(\%, \mathrm{n})$ & $8.8,58$ \\
Treated on an end of life care pathway $(\%, \mathrm{n})$ & $5.6,37$ \\
Referred to Specialist Palliative Care $(\%, \mathrm{n})$ & $6.7,44$ \\
Decision recorded for resuscitation $(\%, \mathrm{n})$ & $32.5,215$ \\
In-hospital mortality (\%, n) & $7.7,51$ \\
Discharged to residential care (\%, n) & $51.4,339$ \\
Discharged home (\%, n) & $31.7,209$ \\
New institutionalization post-discharge $(\%, \mathrm{n})$ & 35,144 \\
Length of Stay (Median, IQR) & $12,7-28$ \\
\hline
\end{tabular}

\section{Multidisciplinary assessment}

In terms of physical assessment, this audit investigated whether or not patients received assessments of functioning (ADLs), nutrition, body mass index (BMI), mobility, continence, pain and pressure sore risk. As can be seen in Fig. 1, assessment of functioning and BMI was quite poor, with less than $40 \%$ of patients receiving these assessments. Mobility, continence and pressure sore risk assessments were performed more regularly, with over $80 \%$ of patients receiving these assessments. There is no record in almost one-quarter of the sample, of the person being asked about the presence of pain, or of any standardised pain assessment.

A gap was noted between hospital policy regarding physical assessments for people with dementia, and actual assessments carried out in practice. While $36 \%$ of patients received a standardised assessment of functioning, $60 \%$ of hospitals responded that it is policy that such an assessment should be carried out on all inpatients with dementia. Just over $75 \%$ of patients received an assessment of nutrition; however $94 \%$ of hospitals reported that all patients with dementia should receive this during an admission. Further, $39 \%$ of patients had their BMI recorded, but $86 \%$ of hospitals reported that this should always be recorded for patients with dementia.

This audit investigated whether assessments of cognition, delirium, BPSD and mood were carried out, and if collateral (informant) history was collected from a carer/relative. As seen in Fig. 2, less than half of patients received any of the mental assessments listed, with particularly low assessment of mood and BPSD, both at $14 \%$. 


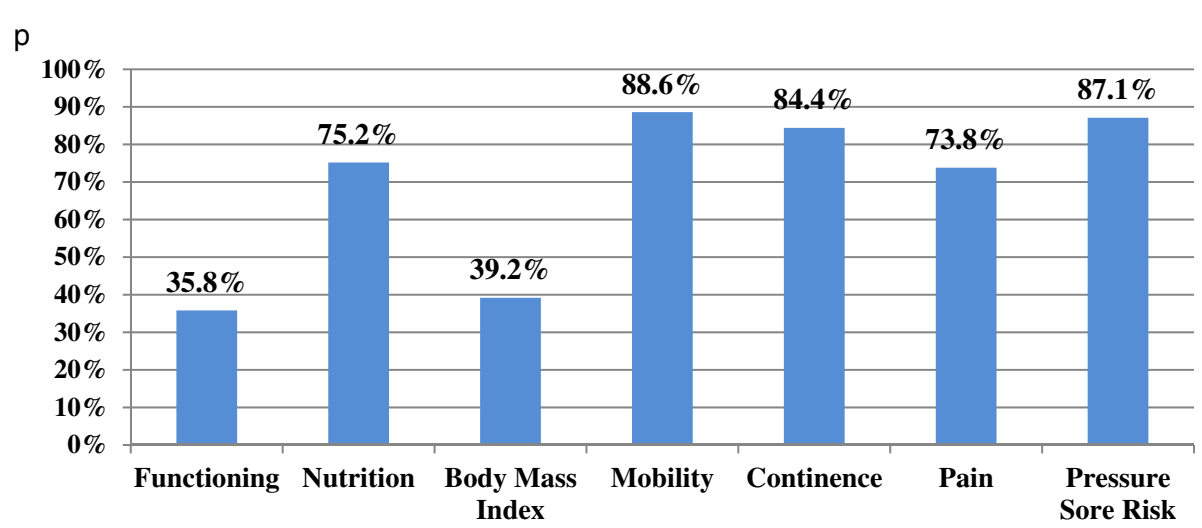

Fig. 1 Physical Assessments Received by Patients with Dementia during Admission ( $n=660)$

The frequency of physical and mental assessments completed was investigated by hospital size (bed capacity), and as seen in Table 3; the largest hospitals completed delirium screens, BPSD and mood assessments, and collected collateral history most often, while the smallest hospitals completed assessments of functioning, nutrition and cognition most often. However, large variation was observed between hospitals within each hospital size group (Table 3).

Highlighting further disparity between policy and practice for mental assessment, $62.9 \%$ of hospitals reported that all patients with dementia should receive a cognitive assessment, but only $42.9 \%$ of patients actually had their cognition assessed during the admission. No collateral history regarding cognitive decline, time since the onset of memory problems, the nature of the disease progression, or loss of function, was collected for over half of patients (52.3\%), despite $62.9 \%$ of hospitals reporting that a collateral history is collected for every patient with dementia.

\section{Specialist services}

The majority of the 77 wards audited had access to specialist services at least 5 days per week, including Liaison Psychiatry, Geriatric Medicine, Occupational Therapy, Physiotherapy, Specialist Infection Control, and Specialist Palliative Care. Ward access to Continence Services and Social Work was poorer, and access to Psychology services is extremely limited (see Table 4). Further investigation into these services revealed that ward managers' reports of availability differ across wards within the same hospitals e.g. $8.6 \%$ of wards disagreed about the availability of Social Work and Psychology, and $17.1 \%$ disagreed about Continence Services.

\section{Staffing training \& support}

A knowledge and training framework/strategy identifying necessary skill development for staff working with people with dementia was only in place in $21.2 \%$ of hospitals. Only 2 hospitals included dementia awareness training on their staff induction programmes; however no hospital had

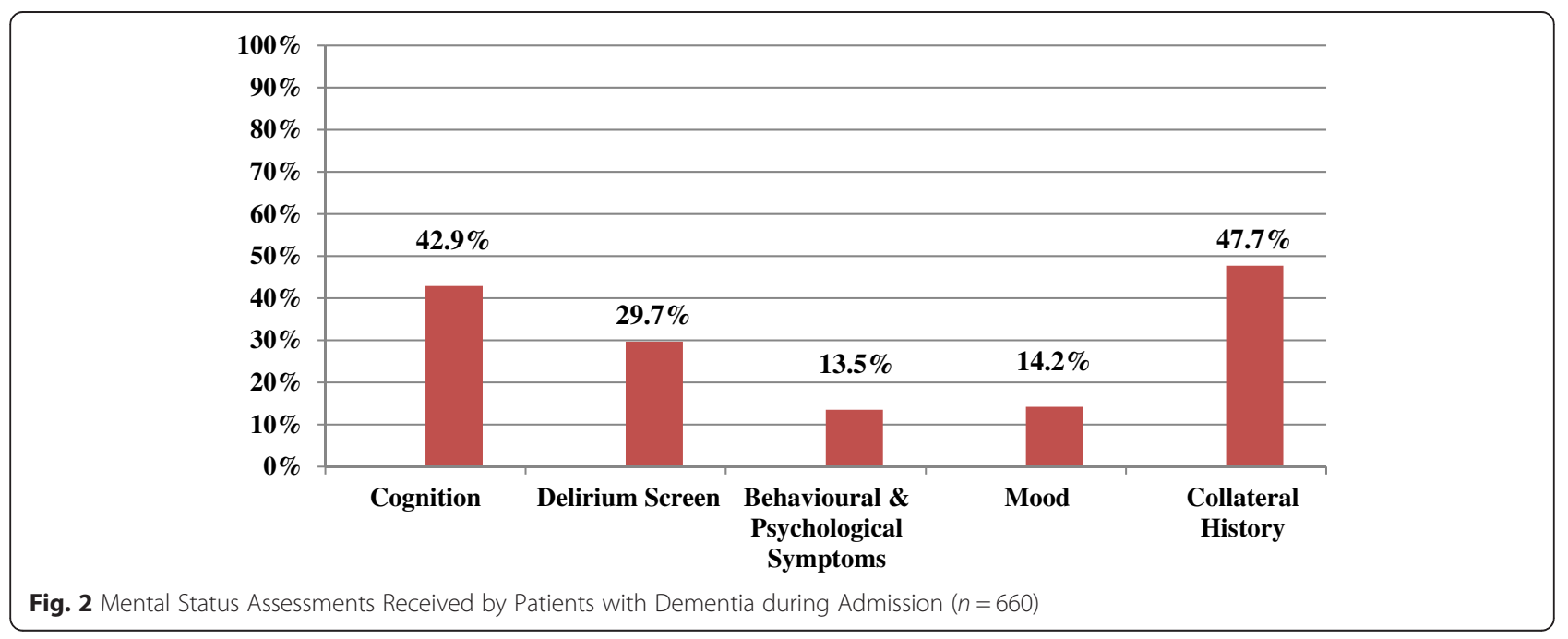


Table 3 Assessments completed ( $n=660)$ by hospital size (Bed Capacity)

\begin{tabular}{|c|c|c|c|c|}
\hline$\%$ (\% range) & $80-150(n=173)$ & $151-300(n=178)$ & $301-600(n=212)$ & $601-1000(n=97)$ \\
\hline \multicolumn{5}{|l|}{ Physical Assessment } \\
\hline Functioning & $44(20-100)$ & $41(10-88)$ & $36(10-100)$ & $15(5-30)$ \\
\hline Nutrition & $83(47-95)$ & $80(48-84)$ & $72(29-90)$ & $66(40-85)$ \\
\hline $\mathrm{BMI}$ & $66(8-94)$ & $47(11-81)$ & $44(29-100)$ & $46(25-63)$ \\
\hline Mobility & $84(50-100)$ & $88(71-100)$ & $93(76-100)$ & $91(75-100)$ \\
\hline Continence & $89(73-100)$ & $84(52-100)$ & $82(20-100)$ & $83(50-100)$ \\
\hline Pain & $65(10-100)$ & $77(40-95)$ & $80(55-100)$ & $74(60-90)$ \\
\hline Pressure Sore Risk & $84(5-100)$ & $93(90-100)$ & $84(40-100)$ & $88(65-100)$ \\
\hline \multicolumn{5}{|l|}{ Mental Assessment } \\
\hline Cognition & $50(9-95)$ & $45(19-75)$ & $38(10-55)$ & $39(20-53)$ \\
\hline Delirium Screen & $23(0-100)$ & $18(10-30)$ & $37(5-65)$ & $48(20-75)$ \\
\hline Behavioural \& Psychological Symptoms & $9(0-41)$ & $10(0-25)$ & $14(0-25)$ & $28(15-59)$ \\
\hline Mood & $15(0-100)$ & $10(0-20)$ & $14(0-59)$ & $23(10-41)$ \\
\hline Collateral History & $29(13-53)$ & $34(20-56)$ & $62(35-82)$ & $74(60-94)$ \\
\hline
\end{tabular}

mandatory dementia awareness training. Hospitals were asked if they had offered this dementia training to staff in the last 12 months (see Fig. 3), with just over half offering to nurses $(51.6 \%)$ and doctors (54.5\%). Other types of specific training in dementia were poorly provided by hospitals for both doctors and nurses respectively, in areas including capacity assessment (37.1\%, $20 \%)$, hearing and visual impairment (8.6 \%, $5.7 \%)$, communication skills (5.7\%, $22.9 \%$ ), and behaviours that challenge (45.7\%, $57.1 \%)$. The majority of ward managers $(62.3 \%)$ reported that

Table 4 Ward access to specialist services $(n=77)$

\begin{tabular}{lllll}
\hline Speciality service & $\begin{array}{l}\text { No } \\
\text { access }\end{array}$ & Limited $^{\mathrm{a}}$ & $\begin{array}{l}\text { Monday- } \\
\text { Friday }\end{array}$ & $\begin{array}{l}\text { Monday- } \\
\text { Sunday }\end{array}$ \\
\hline Liaison Psychiatry & $4 \%$ & $3 \%$ & $42 \%$ & $51 \%$ \\
Psychiatry of Old & $26 \%$ & $3 \%$ & $58 \%$ & $13 \%$ \\
Age & & - & $52 \%$ & $32 \%$ \\
Geriatric Medicine & $16 \%$ & - & $79 \%$ & - \\
Occupational & $21 \%$ & - & $52 \%$ & $1 \%$ \\
Therapy & $47 \%$ & - & $32 \%$ & $67 \%$ \\
Social Work & $0 \%$ & $1 \%$ & $48 \%$ \\
Pharmacy & $0 \%$ & $1 \%$ & $51 \%$ & - \\
Physiotherapy & $7 \%$ & $5 \%$ & $88 \%$ & - \\
Dietetics & $9 \%$ & $10 \%$ & $81 \%$ & - \\
Speech \& & & & & $33 \%$ \\
Language & $91 \%$ & - & $9 \%$ & $1 \%$ \\
Psychology & $1 \%$ & $3 \%$ & $63 \%$ & - \\
Infection Control & $29 \%$ & $16 \%$ & $54 \%$ & $26 \%$ \\
Tissue Viability & $66 \%$ & $8 \%$ & $26 \%$ & \\
Continence & $3 \%$ & $8 \%$ & $21 \%$ & \\
Palliative Care & $3 \%$ &
\end{tabular}

a'Limited' access refers to 3 or less days per week cover could not be given for a staff member on the ward to attend training relating to dementia care.

There were registered nursing staff vacancies on $35 \%$ of wards; however $69 \%$ of wards had at least one vacancy between their permanent healthcare and nursing staff. The mean number of nursing vacancies on wards was 1.83 $(\mathrm{SD}=2.13)$ with a minimum of 0 and a maximum of 9 .

The audit also investigated the types of supports available to staff on the wards caring for people with dementia (see Fig. 4), finding that appraisal and mentorship was not provided for nurses on $80 \%$ of wards, and not provided for over $90 \%$ of healthcare assistants. Over $60 \%$ of nursing staff did not have access to clinical supervision, and $84 \%$ of wards reported that no staff had access to guidance and support from a dementia champion with specialised knowledge and skills regarding best practice in the provision of dementia care. Finally, staff on the majority of the wards had no access to peer support groups (88\%) or reflective practice groups (95\%).

\section{Discharge planning and discharge}

Discharge planning was not initiated within $24 \mathrm{~h}$ of admission for $72.2 \%$ of patients, and only $39.1 \%$ had a single plan for discharge with clear updated information in their chart. Only $30 \%$ of patients had a named person co-ordinating their discharge. In the discharge summary, $32.5 \%$ of patients had their support needs identified, $9.8 \%$ had their level of cognitive impairment noted, and $34.9 \%$ had the cause of impairment noted. Of those that had symptoms of delirium during the admission, $24.2 \%$ had them summarised in their discharge summary, and of those who had symptoms of BPSD, $26.6 \%$ had them summarised. 


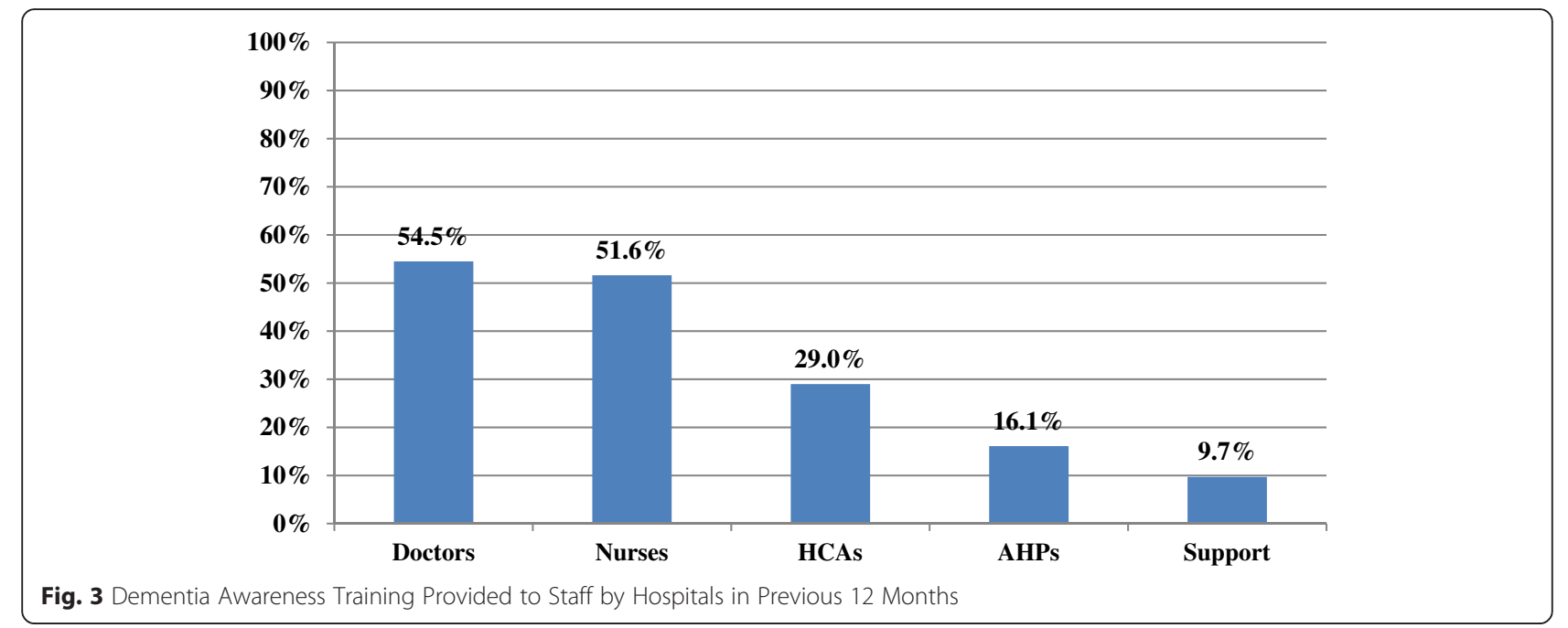

Carers needs (32.9 \%) were infrequently assessed in advance of discharge. The appropriate place of discharge was discussed with $20.9 \%$ of patients and $50.3 \%$ of carers/relatives. Less than half of carers/relatives $(41.3 \%)$ received $24 \mathrm{~h}$ or more notice of discharge and only $11.6 \%$ were given a copy of the patients' discharge summary.

\section{Discussion}

The objective of this audit was to investigate, for the first time, the quality of dementia care across all 35 acute public hospitals in the Republic of Ireland.

Generally, high levels of physical assessments were carried out, echoing findings relating to hospital dementia care in England and Wales [15, 16, 24] particularly for mobility, continence needs, and pressure sore risk; however a standardised assessment of functioning was carried out on only $36 \%$ of patients with dementia. Assessing for changes in functional ability is important for prognostication, minimising hospital associated disability, and predicting mortality and other health outcomes during and after hospitalization [25], as well as for determining dependency to secure an adequate care package after discharge. All older patients, particularly those with dementia, should receive a standardized assessment of their functional ability during hospital admission.

Assessment for the presence of pain was poor, with almost one-quarter of patients not being asked about the presence of pain, or receiving any formal assessment. This reflects previous findings that pain is underassessed in people with dementia $[15,24,26]$. Pain is common in older people with dementia, with up to $45 \%$ experiencing pain [27]. While patients with dementia

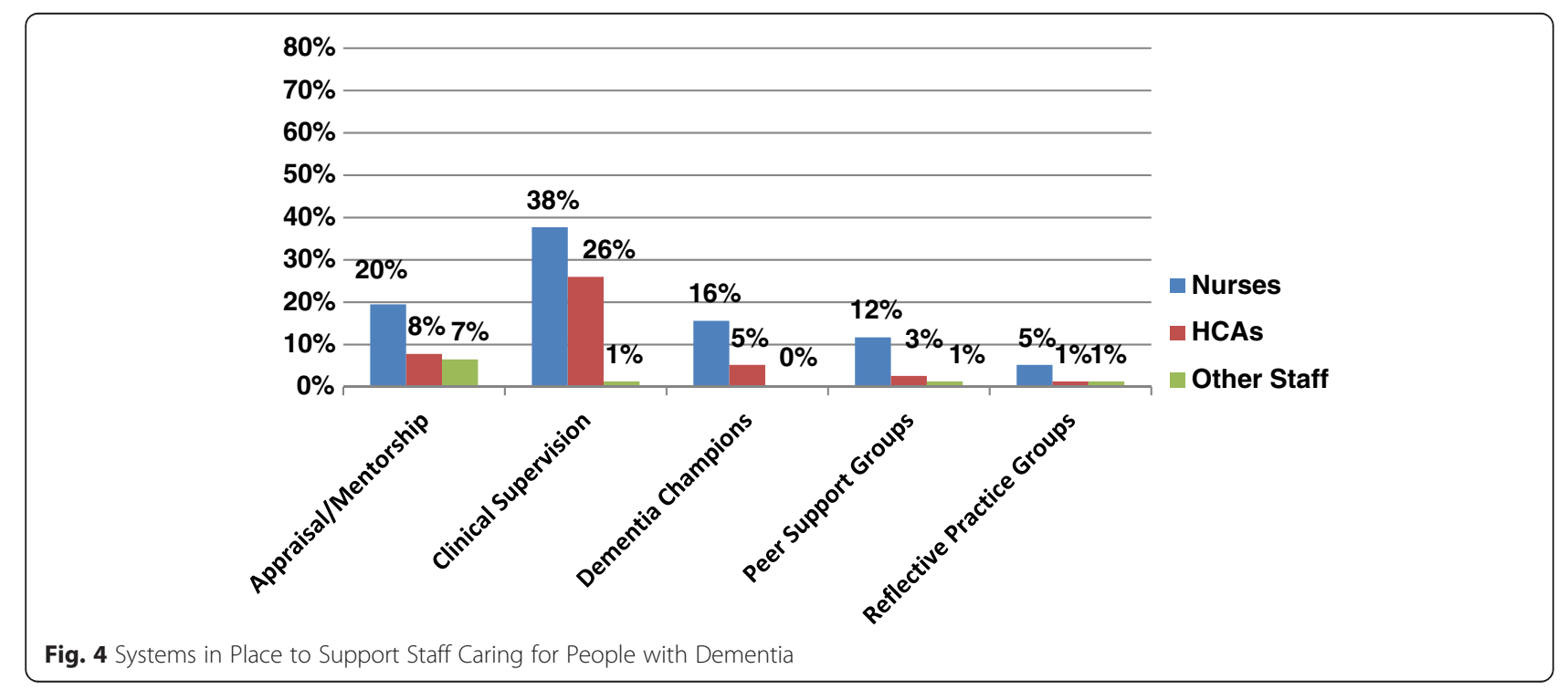


may not always be capable of communicating pain through self-report, pain can be assessed with tools through caregiver report and direct observation [28]. There are a number of validated tools that assess for indicators of pain, including the Pain Assessment in Advanced Dementia Scale [29]; such tools should be used in cases where verbal communication is not possible.

Mental status assessment was poor, which other research has found in this population [24] in a sample of 7934 people. Despite the fact that this sample had a known diagnosis of dementia, just over $40 \%$ had any assessment of cognition, reflecting other findings in Ireland (55 \%) [30], and in England and Wales (43\%) [15]. Cognitive assessment is vital in people with dementia to track course and prognosis, and determine the supports needed to manage the condition [31]. This population are also at high risk of developing delirium [32], however less than $30 \%$ of patients were screened during their admission. Poor hospital delirium screening in dementia has been reported in other countries $[16,33-35]$. Delirium superimposed on dementia is related to adverse outcomes including increased functional dependence, institutionalisation and mortality [36]. According to NICE guidelines [37], screening for fluctuations in behaviour should be carried out at least daily in the acute setting. The absence of this in over $70 \%$ of charts reflects particularly poor practice in the care of a population at high risk of delirium onset.

Mood and BPSD were only assessed in $14 \%$ of patients. Under-recognition and assessment of BPSD is common [38]. BPSD, including depression, are experienced by 66$97 \%$ of people with dementia during the course of their condition [39]. Undetected and untreated symptoms can lead to significant caregiver burden [40] and consequently, earlier institutionalisation. Finally, less than half of patients had any collateral history recorded in their charts. This is imperative for the comprehensive assessment of change from baseline across a number of domains [41] and is central to treatment and prognostication.

Regarding hospital size, operationalised by bed capacity, the largest hospitals were more likely to carry out delirium screening and BPSD and mood assessments, and record collateral history, than the smallest hospitals. However, the largest hospitals were poorer at carrying out assessments of functioning and nutrition; the smallest hospitals these assessments more frequently. Cognitive assessments were completed most frequently in smaller hospitals. While these findings indicate important trends in dementia care by hospital size, bed capacity provides limited information for service planners about how to improve the quality of dementia care, as this approach does not account for organisational factors including the individual services provided within hospitals or the flexibility of staffing based on fluctuating demand
$[42,43]$. This is highlighted here by the large variation in assessments completed between the hospitals within each hospital size group, where resources would be expected to be reasonably similar.

There was a disparity between hospital policy regarding assessment for cognition, functional ability, nutritional status and BMI, and actual assessment in practice. In order to improve multidisciplinary assessment in hospital dementia care, better governance must happen at the hospital level; policies and guidelines must be put in place and enforced in practice at ward level. It is important that this issue of under-assessment, particularly mental assessments, for people with dementia is addressed in Irish hospitals; poor quality acute care has been suggested as contributing to an increased risk of adverse outcomes for older adults including those with dementia [44] Furthermore, those with dementia have an increased cost of care when admitted to hospital, due to greater lengths of stay compared to those without dementia [45]; improvements in multidisciplinary assessments to detect physical and mental problems would likely reduce the length of stay and consequently, cost of care.

According to ward managers, there was very poor access to psychology, continence services and social work, with 91,66 , and $47 \%$ of wards reporting no access to these services respectively. People with dementia can have complex physical and psychosocial needs, particularly during a distressing hospital admission, and these services are vital to providing best care. Of note, there was some disagreement between wards in the same hospital about access to the above services, $9 \%$ of wards disagreed about the availability of psychology and social work within the same hospital, and $17 \%$ disagreed about continence services. This lack of clarity about the availability of services is reflective of fragmentation and a lack of coordination between different levels and settings of care [46]. Better communication is needed between hospital level and ward level management about which services are available within their hospitals. Much better access to pharmacy, physiotherapy, dietetics, speech and language therapy, occupational therapy, liaison psychiatry, and palliative care was reported. Future research should investigate the impact of specialist service availability in acute hospitals on the care and health outcomes of people with dementia, as well as the issue of fragmentation in relation to specialist services.

The provision of dementia awareness training is poor across hospitals; only two hospitals included it in their induction programmes. None of the 35 hospitals had mandatory training for any staff in dementia awareness, indicating that it is not currently considered a priority. Just over half of hospitals had dementia awareness training available to their nurses and doctors over the previous 12 months. However, almost two-thirds of ward 
managers reported that staff cover could not be provided for training relating to dementia care, indicating that staffing levels and lack of resources may be a barrier to staff attending any available training. This picture of inadequate dementia training provision for healthcare staff in acute settings has been found elsewhere also [15, 47]. Dementia awareness training should be mandatory for all staff that care for people with dementia in Ireland as it is integral to increasing overall quality of care and reducing staff burden.

Almost $70 \%$ of wards had at least one vacancy between their permanent healthcare and nursing staff, and the mean number of nursing vacancies was 1.83 , with a maximum of nine nursing vacancies. Lower staffing levels in hospital have been associated with reports of poorer quality care and nurse burnout, as well as adverse patient outcomes including higher mortality [48]. Low staffing levels arise from systemic problems, however in an effort to improve services for dementia, more resources will need to be allocated to ensure sufficient nurse-patient staffing ratios in hospitals.

There are very few supports in place for staff working with people with dementia, with mentorship and clinical supervision not available on 78 and $56 \%$ of wards respectively. Further, peer support groups or reflective practice groups were not available to staff on 88 and $95 \%$ of wards, and $84 \%$ had no dementia champion to provide guidance on issues relating to dementia care. Dementia champion training is now available in Ireland, and so the number of hospitals with dementia champions may increase significantly in the near future. Perceived support from coworkers is important, and has been shown to enhance job performance and decrease the job stress among nursing staff [49]. It is important that management take responsibility for putting supports in place for staff caring for people with dementia to prevent burnout.

Discharge planning was quite poor; the majority of planning (72\%) was not initiated within $24 \mathrm{~h}$ of admission, and only $39 \%$ of patients had a single detailed plan for discharge in their charts. The literature indicates that good discharge planning is imperative; inefficient planning is associated with adverse patient outcomes, increased length of stay, re-admission, and cost $[22,50]$.

Discharge destination was linked to LOS in this sample; the average LOS was 24.73 days, however further investigation revealed that those newly discharged to residential care had a significantly greater LOS than those not requiring such placement. The discharge of $35 \%$ of people with dementia originally admitted from home to long term care in this sample is high compared to $11.5 \%$ of older people without dementia in a recent study also carried out in 5 acute public hospitals [7]. This finding indicates that acute hospitals may be serving as an access point for entry to long term care for people with dementia struggling in the community. Overall, these findings suggest that the system for planning discharge teamed with poor availability of suitable residential placement for people with dementia is problematic in acute hospitals in Ireland, and is contributing to an increased LOS and consequently, greater cost of dementia care.

The results also indicated poor summarising of information, for example support needs, level/cause of cognitive impairment, and delirium and BPSD at discharge. This is poor practice, as the gap between hospital and community care is then not bridged and health outcomes cannot be effectively maintained or improved [22]. A more integrated approach to care across settings is required in order to reduce the unnecessary use of hospital beds once the patient is medically fit for discharge; this includes improved discharge planning, e.g. building relationships with post-acute care providers, and developing shared information systems to facilitate speedy transition [51].

Carer's needs were found to be poorly assessed prior to discharge also, and they were found to have short notice of discharge. This is in line with reports that postdischarge, families feel ill-equipped to take on the carer role, and feel that staff neglected the component of discharge planning relating to accessing assistance and resources in the community [52]. Assessing carer support needs prior to discharge is important as caregiver burden is a risk for early institutionalisation [53].

This study has some limitations; the chart review data has been collected retrospectively, and these findings reflect what has been recorded in the charts. Theoretically, care relating to multidisciplinary assessment and discharge planning may have been better in practice; however any failure to record such information is a failure in communicating essential healthcare information to colleagues, which is, in and of itself, poor practice.

\section{Conclusion}

Dementia care relating to assessment, access to certain specialist services, staffing levels, training and support, and discharge planning is suboptimal, which is likely to increase the risk of adverse patient outcomes and the cost of acute dementia care. Going forward, we must ensure that suitable pathways, policies and care practices are put in place to meet the complex needs of dementia patients to improve the overall quality of acute care provision.

\section{Abbreviations}

BPSD, behavioural and psychological symptoms of dementia; LOS, length of stay; HIPE, hospital in-patient enquiry; HSE, Health Service Executive; IQR, interquartile range; $\mathrm{BMI}$, body mass index. 


\section{Funding}

This audit was supported by a grant from Atlantic Philanthropies. Atlantic Philanthropies had no role in the design of the study, in the collection, analysis, and interpretation of data, or in writing the manuscript.

\section{Availability of data and materials}

The dataset will not be made available; while the data is anonymised, the dataset contains a number of variables relating to hospital, clinician and patient characteristics, which taken together, potentially increase the risk of identifiability of the individuals/hospitals involved.

\section{Authors' contributions}

ST, DoN, SK and PG conceived of the study and drafted the manuscript. EoS, AdeS PG and DMCA collected the data and drafted the manuscript. EoS and AdeS performed the statistical analysis. All authors read and approved the final manuscript.

\section{Competing interests}

The authors declare that they have no competing interests.

\section{Consent for publication}

Not Applicable.

\section{Ethics approval and consent to participate} Not Applicable.

\section{Author details}

${ }^{1}$ Centre for Gerontology and Rehabilitation, School of Medicine, University College Cork, The Bungalow, Block 13, St. Finbarr's Hospital, Douglas Road, Cork, Ireland. ${ }^{2}$ Centre for Ageing, Neuroscience and the Humanities, Trinity Centre for Health Sciences, Tallaght Hospital, Dublin, Ireland. ${ }^{3}$ Quality and Patient Safety Audit Services, Health Service Executive, Dublin, Ireland.

\section{Received: 4 November 2015 Accepted: 27 May 2016}

\section{Published online: 31 May 2016}

\section{References}

1. Cahill S, O'Shea E, Pierce M. Creating Excellence in dementia care: A research review for Ireland's national dementia strategy. Trinity College Dublin, National University of Ireland Galway; 2012.http://dementia.ie/ images/uploads/site-images/creating_excellence_in_dementia_care_2012. pdf. Accessed on 22 June 2015.

2. World Health Organization. Dementia: A public health priority. 2012. http:// apps.who.int/iris/bitstream/10665/75263/1/9789241564458_eng.pdf?ua=1. Accessed on 23 June 2015

3. Mukaetova-Ladinska EB, Teodorczuk A, Cerejeira JM. Dementia in the acute hospital. Brit J Psychiat. 2009;195(5):461-2.

4. Timmons S, Barrett A, Browne V, Manning E, Cahill S, O' Sullivan K, Woods N, Meagher D, O Regan N, Molloy DW, Linehan J. A multi-hospital study of dementia in older people admitted to acute hospitals: prevalence, associations and long term outcomes (Cork Dementia Study). Ir Ageing Stud Rev. 2015;6(1):105

5. Sampson EL, Blanchard MR, Jones L, Tookman A, King M. Dementia in the acute hospital: prospective cohort study of prevalence and mortality. Brit $J$ Psychiat. 2009;195(1):61-6.

6. Andrews J. A guide to creating a dementia-friendly ward. Nurs Times. 2013:109(8):20-1.

7. Manning E, Timmons S, Barrett A, Browne V, Molloy DW, O' Regan N, Cahill S, Linehan J, O' Sullivan K, Woods N, Meagher D, Ni Chorcorain A. The Influence of Dementia on One-Year Mortality Following Hospital Admission, and Place and Cause of Death. Irish J Med Sci. 2014; 183(7): 319-320.

8. De Siun A, O'Shea E, Timmons S, McArdle D, Gibbons P, O' Neill D, Kennelly SP, Gallagher P. Irish national audit of dementia care in acute hospitals. University College Cork and Trinity College Dublin; 2014. http://www.ucc.ie/ en/media/research/irishnationalauditofdementia/INADFullReportLR.pdf. Accessed 2 Feb 2016.

9. Borbasi S, Jones J, Lockwood C, Emden C. Health professionals' perspectives of providing care to people with dementia in the acute setting: Toward better practice. Geriatr Nurs. 2006;27(5):300-8.
10. Park M, Delaney C, Maas M, Reed D. Using a nursing minimum data set with older patients with dementia in an acute care setting. J Adv Nurs. 2004;47(3):329-39

11. De Siún A, Manning M. National dementia project: Dementia education needs analysis report. Office of the Nursing Service Director, Quality \& Clinical Care Directorate, Health Service Executive. 2010.

12. Gandesha A, Souza R, Chaplin R, Hood C. Adequacy of training in dementia care for acute hospital staff: Aarti Gandesha and colleagues present the results of a national audit to assess how hospital staff from different specialties rated their awareness of the needs of patients with dementia. Nurs Older People. 2012;24(4):26-31.

13. Alzheimer's Society. Counting the cost: Caring for people with dementia on hospital wards. 2009. http://www.alzheimers.org.uk/site/scripts/documents info.php?documentID=1199 Accessed 4 Aug 2014

14. Sourial R, McCusker J, Cole M, Abrahamowicz M. Agitation in demented patients in an acute care hospital: Prevalence, disruptiveness, and staff burden. Int Psychogeriatr. 2001:13(02):183-97.

15. Royal College of Psychiatrists. Report of the National Audit of Dementia Care in General Hospitals. London: Healthcare Quality Improvement Partnership; 2011.

16. Royal College of Psychiatrists. National Audit of Dementia Care in General Hospitals 2012-2013: Second Round Audit Report and Update. London: Healthcare Quality Improvement Partnership; 2013.

17. Corbett A, Husebo B, Malcangio M, Staniland A, Cohen-Mansfield J, Aarsland D, Ballard C. Assessment and treatment of pain in people with dementia. Nat Rev Neurol. 2012;8(5):264-74

18. Harwood RH. Dementia for hospital physicians. Clin Med. 2012;12(1):35-9.

19. Howard R, Ballard C, O'Brien J, Burns A. Guidelines for the management of agitation in dementia. Int J Geriatr Psych. 2001;16(7):714-7.

20. Guijarro R, San Román CM, Gomez-Huelgas R, Villalobos A, Martín M, Guil M, .. Toledo JB. Impact of dementia on hospitalization. Neuroepidemiology. 2010;35(2):101-108.

21. Connolly S, O'Shea E. The impact of dementia on length of stay in acute hospitals in Ireland. Dementia. 2013. DOI:1471301213506922.

22. Bauer M, Fitzgerald L, Haesler E, Manfrin M. Hospital discharge planning for frail older people and their family. Are we delivering best practice? A review of the evidence. J Clin Nurs. 2009:18(18):2539-46.

23. Wong EL, Yam CH, Cheung AW, Leung MC, Chan FW, Wong FY, Yeoh EK. Barriers to effective discharge planning: A qualitative study investigating the perspectives of frontline healthcare professionals. BMC Health Serv Res. 2011;11(1):242.

24. Souza R, Gandesha A, Hood C, Chaplin R, Young J, Crome P, Crawford MJ.. Quality of care for people with dementia in general hospitals: National cross-sectional audit of patient assessment. Clin Med. 2014;14(5):490-4.

25. Covinsky KE, Pierluissi E, Johnston CB. Hospitalization-associated disability: "She was probably able to ambulate, but I'm not sure". J Am Med Assoc 2011:306(16):1782-93.

26. Morrison RS, Siu AL. A comparison of pain and its treatment in advanced dementia and cognitively intact patients with hip fracture. J Pain Symptom Manage. 2010;19(4):240-8.

27. Orgeta V, Orrell M, Edwards RT, Hounsome B, Woods B, REMCARE Team. Self-and carer-rated pain in people with dementia: Influences of pain in carers. J Pain Symptom Manage. 2015:49(6):1042-9.

28. Hadjistavropoulos T, Herr K, Prkachin KM, Craig KD, Gibson SJ, Lukas A, Smith JH. Pain assessment in elderly adults with dementia. Lancet Neurol. 2014;13(12):1216-27.

29. Warden V, Hurley AC, Volicer L. Development and psychometric evaluation of the Pain Assessment in Advanced Dementia (PAINAD) scale. J Am Med Dir Assoc. 2003:4(1):9-15.

30. Afzal N, Buhagiar K, Flood J, Cosgrave M. Quality of end-of-life care for dementia patients during acute hospital admission: A retrospective study in Ireland. Gen Hosp Psychiatry. 2010:32(2):141-6.

31. Atchison TB, Massman PJ, Doody RS. Baseline cognitive function predicts rate of decline in basic-care abilities of individuals with dementia of the Alzheimer's type. Arch Clin Neuropsychol. 2007:22(1):99-107.

32. Ryan DJ, O'Regan NA, Caoimh RÓ, Clare J, O'Connor M, Leonard M, .. Timmons S. Delirium in an adult acute hospital population: predictors, prevalence and detection. BMJ Open. 2013;3(1):e001772.

33. Collins N, Blanchard MR, Tookman A Sampson EL. Detection of delirium in the acute hospital. Age Ageing. 2010;39(1):131-5. 
34. Steis MR, Fick DM. Delirium superimposed on dementia: accuracy of nurse documentation. J Gerontol Nurs. 2012;38(1):32-42.

35. Inouye SK, Foreman MD, Mion LC, Katz KH, Cooney LM. Nurses' recognition of delirium and its symptoms. Comparison of nurse and researcher ratings. Arch Intern Med. 2001;161:2467-73.

36. Morandi A, Davis D, Fick DM, Turco R, Boustani M, Lucchi E, ...Bellelli G. Delirium superimposed on dementia strongly predicts worse outcomes in older rehabilitation inpatients. J Am Med Dir Assoc. 2014;15(5):349-354.

37. National Institute for Health and Clinical Excellence. Delirium: Diagnosis, prevention and management. 2010. https://www.nice.org.uk/guidance/ cg103 Accessed on 26 Jan 2015.

38. Kogoj A, Prokšelj T. Do we know all about behavioral and psychological symptoms of dementia. J Gerontol Geriat Res. 2013;3:e124.

39. Savva GM, Zaccai J, Matthews FE, Davidson JE, McKeith I, Brayne C. Prevalence, correlates and course of behavioural and psychological symptoms of dementia in the population. Br J Psychiatry. 2009;194(3):212-9.

40. Tan $\mathrm{LL}$, Wong $\mathrm{HB}$, Allen $\mathrm{H}$. The impact of neuropsychiatric symptoms of dementia in family and professional caregivers in Singapore. Int Psychogeriatr. 2005;17:253-63.

41. Ramani L, Furmedge DS, Reddy SP. Comprehensive geriatric assessment. $\mathrm{Br}$ J Hosp Med. 2014;75(8):122-5.

42. Rechel B, Wright S, Barlow J, McKee M. Hospital capacity planning: From measuring stocks to modelling flows. Bull World Health Organ. 2010;88(8):632-6.

43. Jones RP. Myths of ideal hospital size. Med J Aust. 2010;193(5):298-300.

44. Creditor MC. Hazards of hospitalization of the elderly. Ann Intern Med. 1993;118:219-23.

45. Lyketsos CG, Sheppard JME, Rabins PV. Dementia in elderly persons in a general hospital. Am J Psychiatry. 2000;157(5):704-7.

46. Montenegro H, Holder R, Ramagem C, Urrutia S, Fabrega R, Tasca R, ... Angelica-Gomes M. Combating health care fragmentation through integrated health service delivery networks in the Americas: Lessons learned. Int J Integr Care. 2011;19(5):5-16.

47. Coffey A, Tyrrell M, Buckley M, Manning E, Browne V, Barrett A, Timmons S A multicentre survey of acute hospital nursing staff training in dementia care. J Clin Nurs. 2014;2(4):39.

48. Rafferty AM, Clarke SP, Coles J, Ball J, James P, McKee M, Aiken LH. Outcomes of variation in hospital nurse staffing in English hospitals: Cross-sectional analysis of survey data and discharge records. Int I Nurs Stud. 2007:44(2):175-82.

49. AbuAlRub RF. Job stress, job performance, and social support among hospital nurses. J Nurs Scholarsh. 2004;36(1):73-8.

50. Abad-Corpa E, Royo-Morales T, Iniesta-Sánchez J, Carrillo-Alcaraz A, Rodríguez-Mondejar JJ, Saez-Soto ÁR, Vivo-Molina M. Evaluation of the effectiveness of hospital discharge planning and follow-up in the primary care of patients with chronic obstructive pulmonary disease. J Clin Nurs. 2013;22(5-6):669-80

51. Philp I, Mills KA, Long JF, Thanvi B, Ghosh K. Reducing hospital bed use by frail older people: results from a systematic review of the literature. Int J Integr Care. 2013;13(4):1-19.

52. Grimmer K, Falco J, Moss J. Becoming a carer for an elderly person after discharge from an acute hospital admission. Internet J Allied Health Sci Pract. 2014;2(4). Retrieved from http://ijahsp.nova.edu/articles/vol2num4/ grimmer-carer\%20issues.pdf.

53. Afram B, Stephan A, Verbeek $H$, Bleijlevens MH, Suhonen R, Sutcliffe $C, \ldots$ Hamers JP. Reasons for institutionalization of people with dementia: informal caregiver reports from 8 european countries. J Am Med Dir Assoc. 2014:15(2):108-116

\section{Submit your next manuscript to BioMed Central and we will help you at every step:}

- We accept pre-submission inquiries

- Our selector tool helps you to find the most relevant journal

- We provide round the clock customer support

- Convenient online submission

- Thorough peer review

- Inclusion in PubMed and all major indexing services

- Maximum visibility for your research

Submit your manuscript at www.biomedcentral.com/submit

C Biomed Central 